\title{
The missing link: On strengthening the relationship between values and attitudes
}

Citation for published version (APA):

Dreezens, E., Martijn, C., Tenbült, P., Kok, G. J., \& de Vries, N. K. (2008). The missing link: On strengthening the relationship between values and attitudes. Basic and Applied Social Psychology, 30(2), 142-152. https://doi.org/10.1080/01973530802209186

Document status and date:

Published: 01/01/2008

DOI:

10.1080/01973530802209186

Document Version:

Publisher's PDF, also known as Version of record

Document license:

Taverne

Please check the document version of this publication:

- A submitted manuscript is the version of the article upon submission and before peer-review. There can be important differences between the submitted version and the official published version of record.

People interested in the research are advised to contact the author for the final version of the publication, or visit the DOI to the publisher's website.

- The final author version and the galley proof are versions of the publication after peer review.

- The final published version features the final layout of the paper including the volume, issue and page numbers.

Link to publication

\footnotetext{
General rights rights.

- You may freely distribute the URL identifying the publication in the public portal. please follow below link for the End User Agreement:

www.umlib.nl/taverne-license

Take down policy

If you believe that this document breaches copyright please contact us at:

repository@maastrichtuniversity.nl

providing details and we will investigate your claim.
}

Copyright and moral rights for the publications made accessible in the public portal are retained by the authors and/or other copyright owners and it is a condition of accessing publications that users recognise and abide by the legal requirements associated with these

- Users may download and print one copy of any publication from the public portal for the purpose of private study or research.

- You may not further distribute the material or use it for any profit-making activity or commercial gain

If the publication is distributed under the terms of Article $25 \mathrm{fa}$ of the Dutch Copyright Act, indicated by the "Taverne" license above, 


\section{The Missing Link: On Strengthening the Relationship Between Values and Attitudes}

Ellen Dreezens , Carolien Martijn , Petra Tenbült , Gerjo Kok \& Nanne K. de Vries

To cite this article: Ellen Dreezens , Carolien Martijn , Petra Tenbült, Gerjo Kok \& Nanne K. de Vries (2008) The Missing Link: On Strengthening the Relationship Between Values and Attitudes, BASIC AND APPLIED SOCIAL PSYCHOLOGY, 30:2, 142-152, DOI: 10.1080/01973530802209186

To link to this article: https://doi.org/10.1080/01973530802209186

曲 Published online: 09 Jul 2008.

Submit your article to this journal $₫$

山 Article views: 859

a

View related articles

Citing articles: 1 View citing articles ¿ð 


\title{
The Missing Link: On Strengthening the Relationship Between Values and Attitudes
}

\author{
Ellen Dreezens, Carolien Martijn, Petra Tenbült, Gerjo Kok, and Nanne K. de Vries \\ Maastricht University, The Netherlands
}

\begin{abstract}
Three experiments that test whether the activation of values may result in a change in the relationship between the activated value and connected attitudes are discussed. Participants were primed with the value universalism and subsequently asked for their attitude toward organically grown food. Our results strongly suggest that values are more likely to significantly influence attitudes when the relevant value is activated and the link between the activated value and attitude is activated as well. However, merely activating a specific value is not sufficient to instigate a significant change in the relationship between a value and its related attitudes.
\end{abstract}

Although lay theories may suggest otherwise, people's values are not always predictive of their attitudes and behavior. In this article, we report on three studies that investigate the relation between values and attitudes. Although we focus on the (lack of a) relation between values and attitudes, a good illustration of the core issue of our research is a classic study of Darley and Batson (1973) on the lack of correspondence between values and behavior. In their Good Samaritan study, Darley and Batson confronted a sample of theology students with an emergency situation that obviously demanded their help. Beforehand, some of these students were instructed to give a short talk on the biblical parable of the Good Samaritan who helped a stranger in need, whereas other students were supposed to present on a topic unrelated to helping behavior. Supposedly, the talk would be recorded in another building and half of the students were pressured to hurry to this building, whereas the other half were not. When the students passed an alley on their way to the other building, they encountered a shabbily dressed person who was obviously in need of help. Overall, $60 \%$ of the participants ignored the victim and, occasionally, a student literally stepped over the victim as he continued on his way. Especially when in a hurry, only $10 \%$ of the students

Correspondence should be sent to Ellen Dreezens, Department of Marketing, Faculty of Economics and Business Administration, Tilburg University, P.O. Box 90153, 5000 LE Tilburg, The Netherlands. E-mail: e.e.a.dreezens@uvt.nl stopped to help. Of the nonhurried students, about two thirds offered their help. In contrast to Darley and Batson's prior expectations, thinking of the biblical parable of a man who was left stripped and beaten and subsequently ignored by priests on their way to church did not raise the likelihood of seminary students to act like Good Samaritans. Darley and Batson concluded that increasing the salience of benevolent and altruistic values, such as helping someone in need, is not necessarily enough to ensure that people do indeed help someone in need.

The main goal of our research is to understand when values are likely to prevail. In contrast to early studies that examined the direct correspondence between values and behavior (i.e., the bystander intervention; see e.g., Darley \& Latané, 1968; Schwartz \& Clausen, 1970), we study an earlier phase of value prevalence. More specifically, we report on three studies that examine under what circumstances people's attitudes and opinions are likely to reflect their personal values. Obviously a wide range of attitude issues is eligible to examine the relation with people's underlying values. For this article, we chose the topic of food innovations. An initial reason for this choice was that new production methods such as genetic modification or organic food production are currently much debated and represent an important issue in society (Bredahl, 1999; Cook, Kerr, \& Moore, 2002; Frewer, Howard, \& Shepherd, 1996; Gaskell, Bauer, Durant, \& Allum, 
1999; Moses, 1999; Shanahan, Scheufele, \& Lee, 2001). A second reason is that, given our main research question on the correspondence between values and attitudes, food choice in general, or the acceptance or rejection of food innovations in particular, does seem to be related to personal values (Lindeman \& Sirelius, 2001; Schifferstein \& Oude Ophuis, 1998). Without denying the influence of more down-to-earth factors such as taste, prize, availability, and nutritional value on food choice and preference, it seems reasonable to assume that food-related attitudes are at least partly affected by ethical considerations.

\section{ATTITUDES AND VALUES}

In everyday life, people are constantly exposed to a large number of objects. Whether the object is a cigarette or tomato soup, or concepts such as war or kindness, people evaluate these objects. The positive or negative evaluations of objects form the attitudes toward them. Attitude objects can be abstract (friendship) or concrete (tulips), as well as individual (George W. Bush) or collective (politicians; Eagly \& Chaiken, 1998). Thus, an attitude can be seen as a disposition to evaluate attitude objects with some degree of favor or disfavor (Eagly \& Chaiken, 1993). In most cases, a specific attitude is not an isolated entity but is embedded into a larger set of related concepts.

Schwartz and Bilsky (1990) described values as (a) concepts or beliefs (b) about desirable end states or behaviors (c) that transcend specific situations, (d) guide the selection or evaluation of behavior, and (e) are ordered by relative importance. A person's value system represents a learned organization of rules for making choices and for resolving conflicts (Rokeach, 1968, pp. 159-160). Values are often seen as the building blocks of attitudes and preferences, and as cognitive structures that represent important motivations (Verplanken \& Holland, 2002). One of the prominent functions of attitudes is to express personal values (Katz, 1960; Maio \& Olson, 1994; Maio, Olson, Allen, \& Bernard, 2001) and attitudes can be influenced by or related to the values that they express. One value can be the basis of many attitudes, and one attitude can be based on multiple values. The attitude toward organically grown food (OGF) could for instance be influenced by the values security (harmony and stability of society and personal relationships) and universalism (respect for all people and for nature). These associations may differ widely across persons and attitude objects, both in their specific content as well as in their number (Eagly \& Chaiken, 1995).

However, there is no one-to-one relationship between values and the attitudes that are connected to them. If people consider the value "nature" an important guideline in their lives, this does not necessarily mean that they have a positive attitude toward recycling and a negative attitude toward driving a car or that they always buy OGF. Even when values are activated at a certain moment in time, this does not necessarily lead people to think about, or reconsider, their attitudes that relate to this value. To some extent, the relationship between values and attitudes and the possible moderators of this relationship have been studied earlier. Snyder and DeBono (as cited in Kristiansen \& Hotte, 1996), for instance, showed that low self monitorspeople who have schematic conceptions of themselves - are more likely to develop attitudes based on their values than high self monitors, who have more clearly articulated conceptions of other people. Furthermore, Johnson and Eagly (1989) suggested that the more linked an attitude is to important values, the smaller its latitude of noncommitment is and the smaller the chances are that new information will be incorporated into the attitude. However, these aforementioned relationships between values, attitudes, and their moderators are usually not very large (Feather, 1988; Rokeach, 1973). Therefore, the main focus of this article is on the reasons for this lack of correspondence between the values that people adhere to and their attitudes.

In this article we try to contribute to an explanation for the often observed absence of correspondence between values and attitudes. We examine whether the awareness of relevance of a value for a certain attitude issue strengthens the relationship between values an attitudes. Of special interest here is a study of Snyder and Kendzierski (1982), who showed that attitudes and behavior will influence each other only when people perceive the relevance between an attitude and behavior. Snyder and Kendzierski asked their participants to take the role of a juror in a sex discrimination case in court. In the experimental condition (the relevance condition), participants were led to believe that their opinion about affirmative action was relevant for their judgment of the sex discrimination case. Participants in the control condition (the accessibility condition) were instructed to just articulate their thoughts about affirmative action. Thus, both groups of participants were asked to think about their attitude toward affirmative action, but only participants in the relevance group were suggested that their attitude should have implications for their judgment. The results of this experiment showed that participants in the relevance condition displayed a stronger relationship between their thoughts about affirmative action and their judgments as a juror. In other words, their attitude-behavior consistency was considerably higher than that of participants in the accessibility condition. This experiment suggests that increasing the accessibility of 
an attitude by retrieving it from memory is not sufficient to influence related behavior. The attitude must also be regarded as relevant for and applicable to the behavior at hand. The implications of this experiment may be translated to the relationship between attitudes and values. Would it not be likely that a value only has an influence on an attitude if the value is perceived as relevant for that specific attitude?

Research by Dreezens (2006) confirms the finding that merely activating a value does not necessary lead to an effect on related attitudes, especially when the relationship between a value and an attitude is not immediately clear to participants. In these studies, participants were asked to describe situations in which the values power or universalism had had and influence on their daily lives. This manipulation was chosen to activate the specific values. However, the results showed that activating the value power or universalism had no effect on related attitudes. Our research focuses on identifying under what conditions values $d o$ relate to attitudes. More specifically, the experiments were designed to test the hypothesis that values must not only be activated to have an effect on attitudes, but people need to see the relevance or link between a certain value and a related attitude. The hypothesized underlying process is as follows: First, a value needs to be activated (made more accessible). Subsequently, if people perceive the relevance between the activated value and the attitude issue at hand, the relation between their value and their attitude judgment will become stronger. In the experiments presented here, we focus on the value universalism (protection and respect for nature and all people) and the attitude toward OGF. Research by Dreezens, Martijn, Tenbült, Kok, and De Vries (2005) already showed that the value universalism is positively related to the attitude toward OGF. However, this correlation, although significant, is usually relatively small (between 0.1 and 0.3 ). We predict a significant increase of the relationship between values and attitudes by suggesting a link between the two concepts.

\section{EXPERIMENT 1}

In the first experiment, the manipulation aimed at activating the value universalism by letting participants engage in a mock "personality test" and then telling them that the result of this personality test showed that they had a universalistic personality. We decided to use a manipulation that was rather unusual, which should enable participants to discount the result that was the outcome of the test. Participants were told that they had to choose a cookie and that their choice reflected their personality. In a pretest, participants rated this cookie-personality test as untrustworthy (on a scale from 1 [very unbelievable] to 10 [very believable], they rated the manipulation a 3.6 on average). This implies that participants in general do not believe that their personality can be predicted on the basis of the cookie they choose. It was anticipated that, because participants did not believe the manipulation, they were not forced to give answers in line with their universalism value but were able to discount the manipulation. After choosing a cookie and receiving the universalistic personal result, some participants were subtly informed that the value universalism had something to do with their attitude toward OGF, whereas other participants did not receive such information. Finally, all participants had to express their attitude toward OGF. We expected that only the participants whose value was activated and who received information about the link between the value and the attitude would show a strong value-attitude correspondence. Participants whose value was activated without suggesting the link between the value and the attitude were not expected to show a stronger value-attitude correspondence.

\section{Method}

\section{Participants}

Sixty-three undergraduate students participated and received a small monetary reward. The mean age of the participants ( 25 male, 38 female) was 21.6 years $(S D=2.32$, range $=19-29)$. The respondents were randomly allocated to the three experimental conditions.

\section{Procedure}

Participants were seated. The experimenter explained the procedure, and participants filled out an informed consent form if they agreed to continue with the experiment. The first task was to complete the Schwartz Value Survey (Schwarz, 1992). Then, the experimenter placed five different cookies in a row on the table in front of them. They were told that they were engaging in a personality test and that their personality could be assessed by the cookie they would choose. After choosing one of the five cookies, participants received their "personal result," which described the personality that fitted with the chosen cookie (which was always a universalistic personality). After this manipulation, participants were asked to fill out a subset of the Schwartz Value Survey (Schwartz \& Huismans, 1995), two filler questionnaires, and a questionnaire about OGF. Finally, participants were thanked, debriefed, and paid.

\section{Manipulations}

After choosing one cookie of five different cookies, participants received a "personal" test result. In reality, 
the personal result was entirely dependent on the experimental condition and not on choice of a cookie. Participants in the control condition received the following "personal result":

You appreciate rules, but you think that they are usually too strict. On the one hand, you like to follow your own destiny, but on the other hand you feel the pressure of people around you to fit in. You try to find your own way in all this, by keeping the rules in the back of your mind, but not giving them too much attention. You like a beer and enjoy eating out with your friends. Words that describe you are: enjoying, sociability and loyal.

In this "personal result" the value universalism or the link between universalism and OGF were not mentioned. However, in the activation condition, the "personal result" did allude to the value universalism:

You are someone who frequently thinks about yourself and your environment a lot. Things like recycling, respect for others and politics are not unfamiliar to you. You are open to other people and you respect their viewpoints. Your priority is to live a happy life, but at the same time take into account your surroundings. Words that describe you are: interested, recycling, involved and enjoying.

In this condition, participants were told that they were a universalistic person. However, nothing suggested a link between universalism and OGF. This link was added in the link condition. The only difference between the activation and the link condition was the replacement of the previous two italicized phrases by honest (ecological) food and honest food, respectively. (In the original materials, these words were not printed in italics.)

\section{Pretest Measurements}

Schwartz Value Survey (Personal Profile IVM Version). The Schwartz Value Survey was used to measure which values participants find important in their lives (Schwartz, 1992). It consists of 10 general values that are divided into 40 subvalues. Participants were given the following instruction: "Here we briefly describe some people. Please read each description and think about how much each person is or is not like you." An example of a question is, "Thinking up new ideas and being creative is important to him. He likes to do things in his own original way." Participants could answer 40 of these questions on a 6-point scale ranging from 1 (not like me at all) to 6 (very much like me). The scores of the subvalues belonging to one general value were averaged to create one single score per general value.

\section{Posttest Measurements}

Schwartz Value Survey. The Dutch version of this survey (Schwartz \& Huismans, 1995) consists of 10 motivational value types (like tradition), which are assessed by asking people to rate how important they find 58 subvalues (like "respect for tradition" and "humble"). Because we were primarily interested in participants' scores on the value universalism, we only asked participants to rate the value universalism $(8$ items) and 4 other values as fillers (power, stimulation, hedonism, tradition). Participants were asked to rate to what extent each of these 25 subvalues was a guiding principle in their lives on a 9-point scale ranging from - 1 (opposite to my values) to 7 (extremely important).

Attitude. Four items were used to assess participant's attitudes toward OGF. Participants were asked to rate "What do you in general think about OGF" on four 7-point scales varying from 1 (very unpleasant/very bad/very unfavorable/very negative) to 7 (very pleasant/very good/very favorable/very positive).

Credibility. After the manipulation, participants were asked two questions: "How credible did you think the personal test result was?" and "How credible did you find the idea that we could predict your personality on the basis of the cookie that you chose," with answering alternatives being very implausible $(-3)$, implausible $(-2)$, somewhat implausible $(-1)$, neutral $(0)$, somewhat plausible (1), plausible (2) and very plausible (3).

\section{Results and Discussion}

\section{Credibility of the Manipulation}

The mean score of the participants on the first manipulation check (credibility of the personal result) was $1.06(S D=1.69)$, indicating that the participants rated the personal result as somewhat plausible. The mean score of the participants on the second manipulation check was $-1.56(S D=1.45)$, implying that the participants rated the link between choosing a cookie and personality implausible. In other words, participants slightly agreed with their personality result but did not believe that their result could be predicted by means of cookie choice.

\section{Attitude Toward OGF}

The first analysis tested for a possible difference between the three conditions in their attitude toward OGF. An analysis of variance (ANOVA) using the OGF attitude as dependent variable and condition as a fixed factor showed no difference between the three 
conditions, $F(2,60)=1.97, n s$, which means that there was no difference between the three conditions on their OGF attitude. The means and standard deviations of the attitude toward OGF are presented in Table 1.

\section{Values}

A second analysis tested for a difference between the three conditions on their post-universalism scores, corrected for differences in universalism on the pretest. We analyzed this with a univariate general linear model (GLM) with the posttest of universalism as dependent variable, condition as fixed factor and the premeasure of universalism as a covariate. This analysis showed that there was no difference between the three conditions on their post-universalism scores, corrected for the pre-universalism scores, $F(2,59)<1$, ns. The means and standard deviations of the value universalism (pre- and posttest) are shown in Table 1.

\section{Attitudes and Values}

For the third analysis, which was meant to test if there was a difference in the relationship between the value universalism and the attitude toward OGF between the three conditions, we constructed a GLM with parameters representing the attitude toward OGF, respectively, as the dependent variable, the three conditions as fixed factor, the posttest of the value universalism as a covariate and containing the interaction between universalism and condition. This analysis showed that the three conditions differed in the relation between universalism and OGF, $F(2,57)=5.93, p<.01$. To investigate which conditions differed from each other, three separate tests for the difference between two correlations were conducted. See Table 1 for the raw correlations between the posttest of the value universalism and the attitude toward OGF.

First, the raw correlations were Fisher-transformed to $z$ scores. Then, the correlations were subjected to pairwise comparisons. The relationship between universalism and OGF was significantly stronger in the link condition than in the control condition $(z=2.56, F=.995, p<.01)$ and significantly stronger in the link condition than in the activation condition $(z=2.79, F=.998, p<.01)$. There was no difference in value-attitude correlations between the control and activation conditions. These results show that the value universalism is more likely to significantly influence the attitude toward OGF when the link between the attitude and the value is stated. However, the mean scores of the postmeasure of the value universalism and of the attitude toward OGF did not differ between the three conditions. Thus, only if the value universalism was activated and if the link between universalism and OGF was suggested, participants showed a strong value-attitude correspondence. We think that the underlying mechanism works as follows: If participants agreed with the personal result that they have a universalistic personality, participants became more positive toward OGF. However, if they disagreed with the personal result and did not consider themselves to have universalistic personalities, they became more negative toward OGF. Thus, in the link condition, participants used their universalism scores as a guideline of how to think about OGF, whereas in the activation and control conditions they did not. However, the manipulation that was used in this experiment can be considered somewhat unusual and unlikely to occur in daily life. Therefore, we designed Experiment 2 to see if these findings could be replicated by making use of another manipulation.

\section{EXPERIMENT 2}

This experiment was designed to test the same hypothesis as in Experiment 1: Activating the value universalism and suggesting a link between universalism and OGF will result in a stronger value-attitude correspondence. However, this time, another manipulation

TABLE 1

Attitude Toward Organically Grown Food (OGF), Pretest and Posttest Scores on Universalism, and Correlations Between OGF and Posttest Universalism per Condition (Experiment 1)

\begin{tabular}{lcccc}
\hline Condition & Attitude OGF & Pretest Universalism & Posttest Universalism & $\begin{array}{c}r \text { Attitude OGF and } \\
\text { Posttest Universalism }\end{array}$ \\
\hline Control $^{a}$ & $M(S D)$ & $M(S D)$ & $4.86(1.01)$ & -.11 \\
Activation $^{b}$ & $5.26(.89)$ & $4.29(.82)$ & $4.65(.75)$ & -.17 \\
Link $^{c}$ & $5.76(.69)$ & $4.10(.61)$ & $4.48(.91)$ & +.64 \\
\hline
\end{tabular}

Note. The pretest universalism scores were measured on a scale from 1 to 6 , whereas the posttest universalism scores were measured on a scale from -1 to 7 .

${ }^{\mathrm{a}} n=21 .{ }^{b} n=22 .{ }^{c} n=20$. 
was used. We wanted to create a situation that was somewhat more in line with situations that people could encounter in their daily lives. Therefore, we chose to activate the value universalism not by letting people choose one out of five cookies but by letting them engage in a mock personality questionnaire. Participants were told that they had to fill out a personality questionnaire that resembled the kind found in women's magazines. These personality questionnaires are often about "how good is your relationship?" "are you in for a career?" or "are you assertive enough?" After completing the personality questionnaire, participants received the same personal result as in the previous experiment. This way, three conditions were again created. In the activation condition, the value universalism was activated, but no link between universalism and OGF was suggested. In the link condition, the value universalism was activated, and a subtle link between universalism and OGF was alluded to. In the control condition, the value universalism was not activated, nor was a link between universalism and OGF suggested.

\section{Method}

\section{Participants}

Fifty-one students participated in return of a small monetary reward. The mean age of the participants (6 male, 45 female) was 20.3 years $(S D=2.12$, range $=18-28)$. The respondents were randomly assigned to one of the three experimental conditions.

\section{Procedure}

Participants were tested individually in 30-min sessions. When entering the laboratory, participants were seated. The experimenter explained the procedure and participants filled out an informed consent form if they agreed to continue with the experiment. The first task was to fill out the Schwartz Value Survey. Thereafter, the personality questionnaire was presented to the participants, consisting of 17 questions. All participants were led to believe that the computer then calculated their "personal result," which was shown on the screen. After this manipulation, participants were again asked to fill out a subset of the Schwartz Value Survey (only the values universalism, power, hedonism, tradition, and stimulation). We were interested only in their scores on universalism; the other four values served as distractions. The last part of the experiment consisted of two filler questionnaires (to disguise that we were interested only in their attitude toward
OGF) and a questionnaire about OGF. Then participants were thanked, debriefed, and paid.

\section{Manipulation}

The personality questionnaire consisted of 17 questions. To activate the value universalism, in 6 of the questions the answers that participants could choose from were different for the control condition than for the activation and link conditions. For example, all participants received the question, "Which organization would you like to be a member of?" In the control condition, the possible answering alternatives were (a) Be sparing with style, (b) SOS sexism, and (c) Union against cursing. Thus, in the control condition none of the answering alternatives had anything to do with universalism. In the activation and link conditions however the alternatives were (a) Greenpeace, (b) SOS sexism, and (c) Union against cursing. The idea behind this manipulation was that the first answer in the activation and the link conditions was related to universalism, whereas none of the answers in the control condition were related to universalism. We argue that the universalistic answer alternative was better known and therefore more appealing and that participants in the activation and link conditions would most likely choose this alternative. We repeated a similar manipulation for 6 of the 17 questions. This way, the value universalism would be activated in the activation and link conditions and not in the control condition. A manipulation check showed that $77 \%$ of the participants chose the universalistic answering alternative four times or more (of the total of six possible times).

The "personal results" were the second part of the activation manipulation. The personal results in the different conditions were exactly the same as the personal results in Experiment 1. In the activation condition, the value universalism was activated, but participants did not receive information linking universalism to OGF. However, in the link condition, both the value universalism and the link to OGF were suggested in the text. In the control condition, the value universalism was not activated, and the link between universalism and OGF was not alluded to.

\section{Pre- and Posttest Measurements}

The measures that were used in Experiment 2 were the same as in Experiment 1, except for one adjustment. In our experiment the attitude toward OGF was measured on 5-point scales instead of 7-point scales. This was done to increase the speed with which these questionnaires could be filled out, because in Experiment 1 participants complained that the attitudes questionnaires took too long. 


\section{Results and Discussion}

\section{Attitude Toward OGF}

The first analysis tested whether for possible a priori differences between the three conditions with respect to their attitude toward OGF. An ANOVA using the OGF attitude as dependent variable and condition as a fixed factor revealed no differences between the three conditions, $F(2,48)=1.43, n s$. The means and standard deviations of the attitude toward OGF are presented in Table 2.

\section{Values}

A second analysis tested for a difference between the three conditions on their universalism scores on the posttest, corrected for differences in universalism on the pretest. We tested this with a univariate GLM with the posttest of universalism as dependent variable, condition as fixed factor, and the pretest measurement of universalism as a covariate. This analysis showed that there was no difference between the three conditions on their post-universalism scores, $F(2,47)<1$. Therefore, we cannot conclude that activation of universalism leads to higher adherence to this value in the activation and link conditions, compared to the control condition. The means and standard deviations of the value universalism (pre- and posttest) are reported in Table 2.

\section{Attitudes and Values}

For the third analysis, which was meant to test if there was a difference in the relationship between the value universalism and the attitude toward OGF between the three conditions, we constructed a GLM with parameters representing the attitude toward OGF as the dependent variable, the three conditions as fixed factor, and the value universalism as a covariate and containing the interaction between universalism and condition. This analysis showed that there was a marginally significant difference in the relation between universalism and OGF between the three conditions, $F(2,45)=2.61, p=.08$. Although this effect was only marginally significant, it was still interpreted because there was a clear prediction of the direction of the effect.

To investigate which conditions differed from each other, three tests for the difference between two correlations were done. The raw correlations between the posttest of universalism and the attitude toward OGF are reported in Table 2. For the analyses, first the correlations were Fisher-transformed to $Z$ scores. Then, the correlations were compared pairwise. The positive relationship between universalism and OGF was (marginally) significantly stronger in the link condition than in the control condition $(z=1.58, F=.943, p=.057)$ and significantly stronger in the link condition than in the activation condition $(z=2.50, F=.994, p<.01)$. The attitude-value correlations in the control and activation conditions did not differ from each other. These results indicated that the relationship with the value universalism became stronger when a link between the attitude and the value was suggested.

In line with Experiment 1, the results of the second experiment suggest that only if the value universalism is activated and if a link between universalism and food preference was suggested, participants showed a strong value-attitude correspondence. Supposedly, participants have actively related the value universalism to their attitude toward OGF. If they felt that they had a universalistic personality, participants became more positive toward OGF. However, if they did not consider themselves universalistic, they became more negative toward OGF. This may have resulted in a significantly stronger relation between the value universalism and the attitude toward OGF, without affecting the mean adherence to this value or attitude.

However, one could argue that participants are using their endorsement of the value universalism as a guide to their attitude judgments primarily because by using the value they will seem more consistent or helpful to the experimenter who, at least in the link conditions, may be expected to think that a value and attitude should be related. Even though we tried to control for such demand characteristics, it could still be the case that

TABLE 2

Attitude Toward Organically Grown Food (OGF), Pretest and Posttest Scores on Universalism, and Correlations Between OGF and Posttest Universalism per Condition (Experiment 2)

\begin{tabular}{lcccr}
\hline & Attitude OGF & Pretest Universalism & Posttest Universalism & \\
\cline { 2 - 4 } Condition & $M(S D)$ & $M(S D)$ & $M(S D)$ & $\begin{array}{r}\text { r Attitude OGF and } \\
\text { Posttest Universalism }\end{array}$ \\
\hline Control $^{\mathrm{a}}$ & $3.77(.56)$ & $3.81(.83)$ & $4.30(1.04)$ & -.04 \\
Activation $^{\mathrm{b}}$ & $4.08(.59)$ & $4.03(.82)$ & $4.38(.74)$ & -.27 \\
Link $^{\mathrm{c}}$ & $3.90(.49)$ & $3.99(.80)$ & $4.61(1.07)$ & .57 \\
\hline
\end{tabular}

Note. The pretest universalism scores were measured on a scale from 1 to 6 , whereas the posttest universalism scores were measured on a scale from -1 to 7 .

${ }^{\mathrm{a}} \mathrm{n}=16 .{ }^{\mathrm{b}} \mathrm{n}=18 .{ }^{\mathrm{c}} \mathrm{n}=17$. 
participants took the linking manipulation as telling them that support for universalism meant that they should also support OGF and that a rejection of the value universalism should also result in a rejection of OGF. This could have led participants to report a correspondence between the two, which was in fact untruthful, or deliberately enhanced. The design of the previous two experiments, where all questionnaires were issued in one session by the one and the same experimenter, could have enhanced the idea that they were related to each other. To further eliminate the effect of demand characteristics, we designed Experiment 3. This experiment was in much the same as Experiment 2. However, we separated the pre- and posttest by giving participants a short break in between, using two different test rooms and two different experimenters. Separating two phases of a study (in time and setting) to decrease the likelihood of demand characteristics accounting for effects of the relevance manipulation was earlier used by Borgida and Campbell (1982) in a study on attitude-behavior consistency. We therefore argue that separating the two phases of the experiment in time, room, and experimenter should be sufficient to diminish the chance of demand characteristics being the main explanation for these findings.

\section{EXPERIMENT 3}

\section{Method}

\section{Participants}

In this study, 60 students participated in return of a monetary reward. The mean age of the participants (15 male, 45 female) was 20.9 years $(S D=1.82$, range $=18-25)$. The respondents were randomly assigned to one of the three experimental conditions (activation, link, or control).

\section{Procedure}

Participants signed up for two, allegedly independent studies. Upon entering the laboratory, participants were welcomed by the first experimenter, signed an informed consent form if they agreed to continue, and received a participant identification number. The first task was to fill out the Schwartz Value Survey. Thereafter, the 17-item personality questionnaire, which was also used as a manipulation in Experiment 2, was presented to the participants. All participants were led to believe that the computer then calculated their "personal result," which was shown on the screen. The personal result differed as a function of condition and was exactly the same as the personal results in Experiments 1 and 2. In the activation condition, the value universalism was activated, but participants did not receive information linking universalism to OGF. In the link condition, both the value universalism and the link to OGF were suggested in the text. In the control condition, the value universalism was not activated, and the link between universalism and OGF was not alluded to. After the premeasurement of values and the manipulation of the relation between a participant's answers on the personality questionnaire and universalism, the participant was asked to go to another room for the supposedly second experiment.

The second experimenter welcomed the participant, explained the second part of the experiment (which was presented as a study on attitudes about a variety of topics), and presented an informed consent form if the participant decided to continue with the study. Participants received again a (different) subject identification number. Subsequently, participants filled out a subset of the Schwartz Value Survey (only the values universalism, power, hedonism, tradition, and stimulation) but with another version of the questionnaire. The last part of the experiment consisted of two filler questionnaires (to disguise that we were only interested in their attitude toward OGF) and a questionnaire about OGF. Finally, each participant was subjected to a brief exit interview to check whether our procedure evoked suspicion about the "unrelatedness" of the two experiments ("In how many studies did you participate today?" "What were the topics of these studies?" "Did you notice anything about these studies?" "Was there anything in these studies that appeared to you as unusual or odd?"). None of the participants provided answers that reflected consciousness of the relation between the two studies. After this, participants were thanked, debriefed, and paid.

\section{Manipulation and Measurements}

The manipulation and the pre- and posttest measurements of Experiment 3 were exactly the same as those in Experiment 2.

\section{Results}

\section{Attitude Toward OGF}

First we tested for a priori differences between the three conditions with respect to their attitudes toward OGF. An ANOVA using the pretest attitude scores as dependent variable and condition as a fixed factor did not reveal a significant difference, $F(2,57)<1$, ns (see Table 3 for means and standard deviations).

\section{Values}

A second analysis tested for a difference between the three conditions on their universalism scores on the posttest, corrected for differences in universalism on 
the pretest. A univariate GLM with posttest scores of universalism as dependent variable, condition as fixed factor, and pretest scores of universalism as a covariate indicated the absence of any differences, $F(2,56)<1$, ns (see Table 3 for means and standard deviations).

\section{Attitudes and Values}

A third set of analyses was conducted to test for differences in the strength of value-attitude relations as a function of condition.

A GLM with parameters representing the attitude toward OGF as dependent variable, the three conditions as fixed factor and posttest scores of universalism as a covariate and containing the interaction between universalism and condition showed a difference in the relation between universalism and OGF between the three conditions, $F(2,54)=3.66, p<.05$.

For the further inspection of this effect, the Fishertransformed correlations per condition between postuniversalism scores and the attitude towards OGF were subjected to three pairwise comparisons (see Table 3 for an overview of raw correlations). Results replicated the findings of Experiments 1 and 2; the positive relationship between universalism and OGF was greater in the link condition than in the control condition $(z=1.99$, $F=.98, p<.05)$ and greater than in the activation condition $(z=1.65, F=.95, p<.05)$. There was no difference in correlations between the control and activation condition $(z=.24, F=.59, n s)$.

\section{GENERAL DISCUSSION}

In attitude theory it is generally assumed that attitudes are related to values, most often through evaluations of outcomes of behavior or characteristics of attitude objects (Eagly \& Chaiken, 1995). Our studies provide an empirical demonstration that values can indeed be related to attitudes, but only when the link between the value and the attitude is clear or made accessible. Taken together, the results of the three experiments reported in this article show that by suggesting that a value and an attitude are related, the value becomes a significant and important predictor for the attitude, or in other words, attitudes come to reflect their underlying values. Even though values are abstract constructs, it seems possible to activate (but not change) them in certain situations. This activation might result in people using value-relevant information in decision making, judgments, and evaluations, on the precondition that they are also aware of the link between values and those judgments.

One could argue that to efficiently test the effect of activating a value on the one hand, and linking a value to an attitude on the other hand, a $2 \times 2$ design would have better suited. However, the reported experiments were carried out with a $3 \times 1$ design. This is because it seems very difficult to suggest a link between a value and an attitude without also activating this value. Suggesting that universalism and OGF are connected automatically results in the activation of the value universalism. Further research should aim at unraveling these assumed components to see whether the effect is an interaction between activating a value and a suggested link between a value and an attitude.

The effect that suggesting a link between a value and an attitude has on the value-attitude correspondence probably mostly holds for value-attitude relations that are weak in the first place. If a value is evidently related to an attitude (e.g., the value health and the attitude toward smoking or the value safety and the attitude toward war), this link effect might have a much smaller impact, because people already realize that the two are connected. Because people often think about their strong attitudes and apply them to a large variety of situations, a strong attitude probably already has been applied to the various situations to which it could be applied to. All the possible connections between this attitude and other concepts, like values, have most likely already been made. In this case, linking an attitude

TABLE 3

Attitude Toward Organically Grown Food (OGF), Pretest and Posttest Scores on Universalism, and Correlations Between OGF and Posttest Universalism per Condition (Experiment 3)

\begin{tabular}{lcccc}
\hline & Attitude OGF & Pretest Universalism & Posttest Universalism & \\
\cline { 2 - 5 } Condition & $M(S D)$ & $M(S D)$ & $M(S D)$ & $\begin{array}{c}\text { r Attitude OGF and } \\
\text { Posttest Universalism }\end{array}$ \\
\hline Control $^{\mathrm{a}}$ & $4.38(.63)$ & $3.96(.43)$ & $3.77(.72)$ & -.18 \\
Activation $^{\mathrm{b}}$ & $4.38(.59)$ & $4.11(.38)$ & $3.79(.72)$ & -.07 \\
Link $^{\mathrm{c}}$ & $4.21(.53)$ & $4.08(.39)$ & $4.07(.79)$ & .56 \\
\hline
\end{tabular}

Note. The pretest universalism scores were measured on a scale from 1 to 6 , whereas the posttest universalism scores were measured on a scale from -1 to 7 .

${ }^{\mathrm{a}} \mathrm{n}=21 .{ }^{\mathrm{b}} \mathrm{n}=20 .{ }^{\mathrm{c}} \mathrm{n}=19$. 
and a value does not have a large influence, because participants already realize that there is a connection between a value and an attitude. For weak attitudes, the whole spectrum of possible relations to other concepts, such as values, has not been explored in so much detail because people rarely think about these attitudes, or apply them in their daily lives on very few occasions. Only the very obvious connections will be clear to the person that holds the attitude. In these cases, linking a value and an attitude can suggest unknown connections to people and linking can have an effect.

These effects are even more meaningful when the minimalist nature of the manipulations is taken into account. By just reminding people in a subtle way that universalism has something to do with OGF, a strong relationship between universalism and OGF is established. This sheds new light on the literature on valueattitude relationships. As Ajzen (1988) argued, values are much less specific than attitudes, and it is therefore difficult to influence attitudes via values. Suggesting a link between these two could have resulted in the bridging of the specificity-gap between values and attitudes. In the literature, this link effect has already been reported concerning the relationship between attitudes and behavior. However, the finding that this reasoning also applies to the connection between values and attitudes is new.

To make a strong case against demand characteristics as an explanation for these findings, we replicated the results Experiment 1 and 2 in a third experiment in which we changed three of its characteristics. First of all, in between the manipulation and measuring the dependent variables, there was a short break. Furthermore, participants were asked to undertake the manipulation in one room and fill in the questionnaires about the dependent variables in another room. Finally, there were two experimenters, one for the manipulation part of the experiment and one for the part where the dependent variables were measured. Altogether, we believe that these three alterations made an explanation based on demand characteristics unlikely. We expect that it was much more difficult for participants to tie the two phases of the experiment together with this setup. Thus, we argue that Experiment 3, where the same pattern of results was found as in Experiments 1 and 2, showed that the effects reported in this article are caused by attitudes reflecting their underlying values more when the link between the two is suggested instead of merely demand characteristics.

Taken together then, our experiments are illustrations of the dilemmas that people come to face in their daily lives. It is never the case that a person finds only one value important in life or that only one value is activated at a certain moment. This was already shown by Darley and Batson (1973) in their experiment on the parable of the Good Samaritan. Even if a value is experimentally activated, it could be that other values, which are of great importance to the person, or that are activated because of the situation, interfere with the experimentally activated value. Linking a value to an attitude issue provides for a way to implicitly show participants that a value and an attitude are related to each other and that an attitude issue can be seen in the light of this value.

\section{ACKNOWLEDGMENTS}

This work was supported by a grant of the Netherlands Organization for Health Research (ZonMw, Grant No. 401-60-001).

\section{REFERENCES}

Ajzen, I. (1988). Attitudes, personality and behaviour. Chicago: Dorsey. Borgida, E., \& Campbell, B. (1982). Belief relevance and attitudebehavior consistency: The moderating role of personal experience. Journal of Personality and Social Psychology, 42, 239-247.

Bredahl, L. (1999). Consumers' cognitions with regard to genetically modified foods: Results of a qualitative study in four countries. Appetite, 33, 343-360.

Cook, A. J., Kerr, G. N., \& Moore, K. (2002). Attitudes and intentions toward purchasing GM food. Journal of Economic Psychology, 23, $557-572$.

Darley, J. M., \& Batson, C. D. (1973). "From Jerusalem to Jericho": A study of situational and dispositional variables in helping behavior. Journal of Personality and Social Psychology, 27, 100-108.

Darley, J. M., \& Latané, B. (1968). When will people help in a crisis? Psychology Today, 2, 54-57, 70-71.

Dreezens, E. (2006). The missing link: The relationship between values and attitudes. Unpublished doctoral dissertation, Universiteit Maastricht, Maastricht, The Netherlands.

Dreezens, E., Martijn, C., Tenbült, P., Kok, G., \& De Vries, N. K. (2005). Food and values: An examination of values underlying attitudes toward genetically modified- and organically grown food products. Appetite, 44, 115-122.

Eagly, A. H., \& Chaiken, S. (1993). The psychology of attitudes. Fort Worth, TX: Harcourt Brace Jovanovich.

Eagly, A. H., \& Chaiken, S. (1995). Attitude strength, attitude structure and resistance to change. In R. E. Petty \& J. A. Krosnick (Eds.), Attitude strength: Antecedents and consequences. Ohio State University series on attitudes and persuasion (Vol. 4). Mahwah, NJ: Erlbaum.

Eagly, A. H., \& Chaiken, S. (1998). Attitude structure and function. In D. T. Gilbert, S. T. Fiske \& G. Lindzey (Eds.), The handbook of social psychology (4th ed., pp. 169-322). New York: McGraw-Hill.

Feather, N. T. (1988). Moral judgement and human values. British Journal of Social Psychology, 27, 239-246.

Frewer, L. J., Howard, C., \& Shepherd, R. (1996). Effective communication about genetic engineering. British Food Journal, 98, 48-52.

Gaskell, G., Bauer, M. W., Durant, J., \& Allum, N. C. (1999). Worlds apart? The reception of genetically modified foods in Europe and the U.S. Science, 285, 384-390.

Johnson, B. T., \& Eagly, A. H. (1989). Effects of involvement on persuasion: A meta-analysis. Psychological Bulletin, 106, 290-314. 
Lindeman, M., \& Sirelius, M. (2001). Food choice ideologies: The modern manifestations of normative and humanist views of the world. Appetite, 37, 175-184.

Katz, D. (1960). The functional approach to the study of attitudes. Public-Opinion-Quarterly, 24, 163-204.

Kristiansen, C. M., \& Hotte, A. M. (1996). Morality and the self: Implications for the when and how of value-attitude-behavior relations. In C. Seligman, J. M. Olson, \& M. P. Zanna (Eds.), The psychology of values: The Ontario symposium (Vol. 8, pp. 77-105). Mahwah, NJ: Erlbaum.

Maio, G. R., \& Olson, J. M. (1994). Value-attitude-behavior relations: The moderation role of attitude functions. British Journal of Social Psychology, 33, 301-312.

Maio, G. R., Olson, J. M., Allen, L., \& Bernard, M. M. (2001). Addressing discrepancies between values and behavior: The motivating effect of reasons. Journal of Experimental Social Psychology, 37,104-117.

Moses, V. (1999). Biotechnology products and European consumers. Biotechnology Advances, 17, 647-678.

Rokeach, M. (1968). Beliefs, attitudes and values: A theory of organization and change. San Francisco: Jossey-Bass.

Rokeach, M. (1973). The nature of human values. New York: Free Press.

Schifferstein, H. N. J., \& Oude Ophuis, P. A. M. (1998). Health-related determinants of organic food consumption in The Netherlands. Food Quality and Preference, 9, 119-133.
Schwartz, S. H. (1992). Universals in the content and structure of values: Theoretical advances and empirical tests in 20 countries. In M. P. Zanna (Ed.), Advances in Experimental Social Psychology (Vol. 25, pp. 1-65). Waterloo, Canada: Academic.

Schwartz, S. H., \& Bilsky, W. (1990). Toward a theory of the universal content and structure of values: Extensions and cross-cultural replications. Journal of Personality and Social Psychology, $58,878-891$.

Schwartz, S. H., \& Clausen, G. T. (1970). Responsibility, norms and helping in an emergency. Journal of Personality and Social Psychology, 16, 299-310.

Schwartz, S. H., \& Huismans, S. (1995). Value priorities and religiosity in four Western religions. Social Psychology Quarterly, 58, 88-107.

Shanahan, J., Scheufele, D., \& Lee, E. (2001). Attitudes about agricultural biotechnology and genetically modified organisms. Public Opinion Quarterly, 65, 267-281.

Snyder, M., \& Kendzierski, D. (1982). Acting on one's attitudes: Procedures for linking attitudes and behavior. Journal of Experimental Social Psychology, 18, 165-183.

Verplanken, B., \& Holland, R. W. (2002). Motivated decision making: Effects of activation and self-centrality of values on choices and behavior. Journal of Personality and Social Psychology, 82, $434-447$. 